MPC MAJOR RESEARCH PAPER

\title{
KEEP IT "REAL": THE CO-CONSTRUCTION OF AUTHENTIC PERFORMANCE AND AUDIENCE CONNECTION IN POETRY SLAM COMPETITIONS
}

by

GLORIA EID

\begin{abstract}
Dr. Catherine Schryer
The Major Research Paper is submitted in partial fulfillment of the requirements for the degree of Master of Professional Communication
\end{abstract}

Ryerson University

Toronto, Ontario, Canada

August 15, 2012 


\section{AUTHOR'S DECLARATION FOR ELECTRONIC SUBMISSION}

I hereby declare that I am the sole author of this thesis. This is a true copy of the thesis, including any required final revisions, as accepted by my examiners.

I authorize Ryerson University to lend this thesis to other institutions or individuals for the purpose of scholarly research.

I further authorize Ryerson University to reproduce this thesis by photocopying or by other means, in total or in part, at the request of other institutions or individuals for the purpose of scholarly research.

I understand that my thesis may be made electronically available to the public. 


\begin{abstract}
KEEP IT "REAL": THE CO-CONSTRUCTION OF AUTHENTIC PERFORMANCE AND AUDIENCE CONNECTION IN POETRY SLAM COMPETITIONS

\author{
Gloria Eid \\ Master of Professional Communication \\ Ryerson University, 2012 \\ Dr. Catherine Schryer
}

With the poetry slam competition - a live, competitive spoken word poetry reading - as context for this project, the study explores the concepts of authenticity and audience connection as they relate to message production and meaning-making processes in the field of professional communication. This project uses a symbolic interactionist perspective and Goffman's (1959) theory of dramaturgy to investigate the poet-audience relationship and discover how a display of authentic performance works to achieve the goal of audience connection. The researcher interviewed six slam poets from the Greater Toronto and Southwestern Ontario area about their experiences in the poetry slam world. Results from the interviews reveal that authenticity is co-constructed between poet and audience, involving a coalescence of private preparation strategies and onstage performance strategies that help craft a sense of credibility and honesty from the poet that, in turn, contribute to achieving successful audience connection by the slam poet as performer. 


\section{TABLE OF CONTENTS}

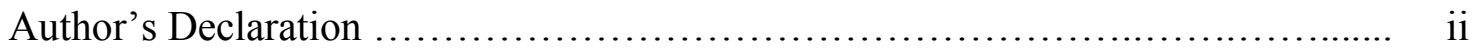

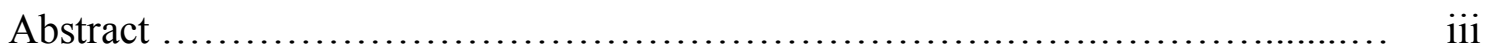

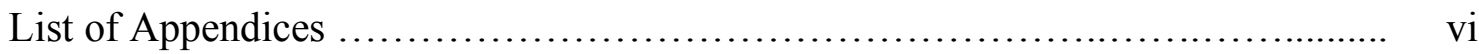

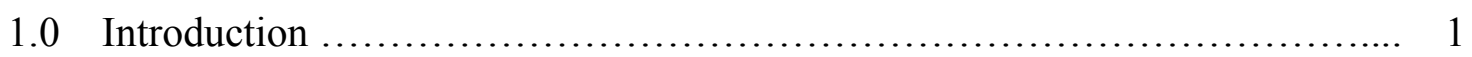

1.1 Significance of Study........................................... 3

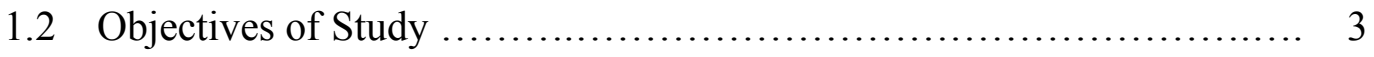

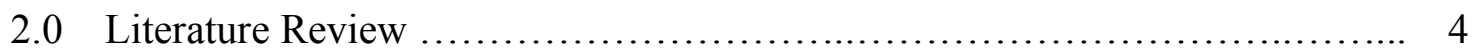

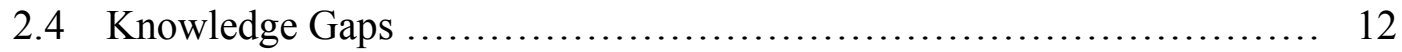

3.0 Theoretical Framework .............................................. 13

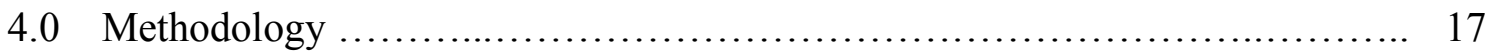

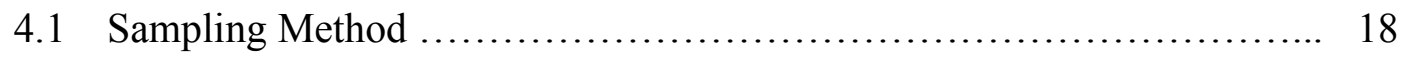

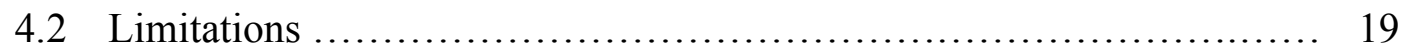

4.3 Participants ................................................. 19

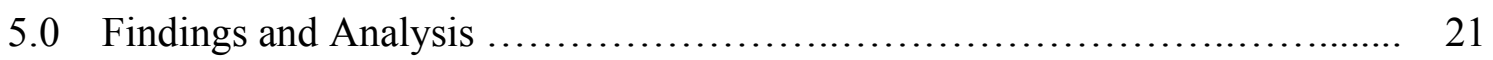

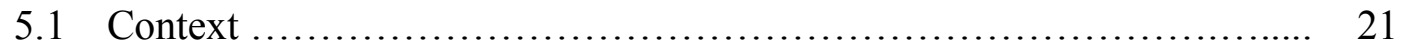

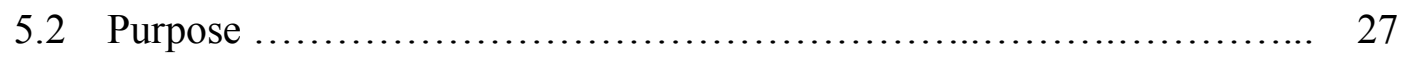

5.2.1 Personal Purpose .......................................... 27

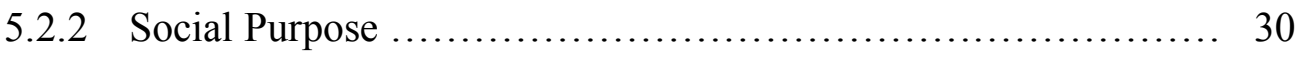

5.2.3 Real Purpose ............................................ 32

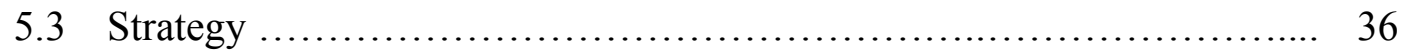

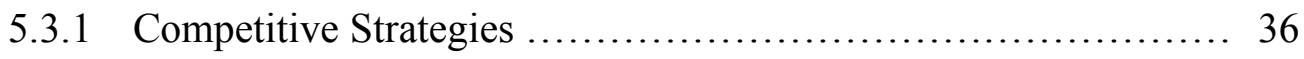

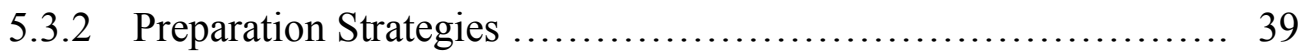


5.3.3 Performance Strategies .................................... 40

5.3.4 Authenticity Strategies .................................... 44

6.0 Discussion and Future Research ............................................ 49

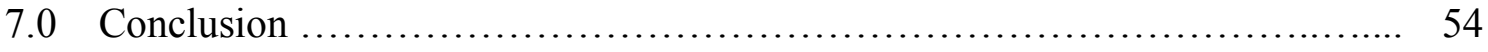

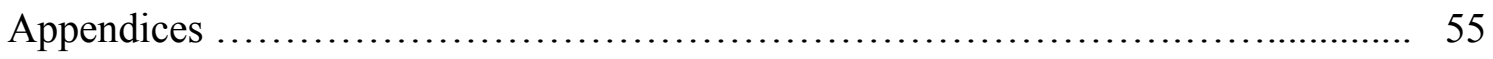

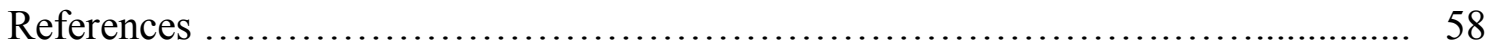




\section{LIST OF APPENDICES}

Appendix 1: Interview Schedule ........................................ 55

Appendix 2: "Pull the Next One Up" by Marc Smith ........................... 56 


\section{The Official National Poetry Slam "Emcee Spiel"}

Ladies and Gentlemen, this is a Poetry Slam. My name is [say your name clearly] and I will be your emcee for the evening. The poetry slam is a competition invented in the 1980s by a Chicago construction worker named Marc Smith ["So what!"] in which performed poetry is judged by five members of the audience. Poets have three minutes to present their original work and may choose to do so accompanied by other members of their team. The Judges will then score the piece anywhere from 0 to 10 , evaluating such qualities as performance, content, and originality. The high and low scores of each performance are tossed, and the middle three are added giving the performer their score. Points are deducted for violating the three-minute time limit. We beseech the judges to remain unswayed by the audience - audience, try to sway the judges - and score each poet by the same set of criteria, ignoring whatever boisterous reaction your judgment elicits. Audience: Let the judges know how you feel about the job they are doing, but be respectful in your exuberance; there could be no show without them. Now let me introduce you to the judges! (Somers-Willet, 2009:149).

\subsection{Introduction}

When a poem is read aloud at a poetry reading, the written content is publicly united with its author's performance - with the tone, gestures, emphasis, and oral interpretation that is not always immediately conveyed on the page. This process of converting words from the page onto the stage creates the multidimensional art form of spoken word poetry, whereby its consumers engage the poetry as public, active participants rather than as private readers.

At a poetry slam - a live, competitive spoken word poetry reading - an intersubjective network arises between poets and audiences during a performance that can often become an intrinsic element of the poem's meaning to the audience. An array of communicative gestures and utterances emerge during slam performances that assist in deciphering the event's meaning at any point in time. For example, a poet's silently raised hand on stage functions as a "trigger warning" about the sensitive content to follow, finger-snaps of encouragement move throughout the crowd as the poet stumbles on a verse, shouts and howls emerge in response to a spiraling lyrical flow, and grunts 
and head nods indicate collective understanding to a poet's hard-hitting line or rightlytimed pause.

But what is it about the relationship between poet and audience that creates this collective understanding? What role does the poet play in the development of a successful connection to audience members? What does 'making a connection' even mean in the slam poetry scene? In a general sense, much of the literature on poetry performance refers to connection as resulting from an audience's belief in the genuine being of the performer during his or her performance (Somers-Willet, 2009; Jones, 2002). As the review of literature will discover, this reference to the "genuine being" is part of the complex and multifaceted notion of creating the performer-audience connection. Nevertheless, Lowney (2009) insists that "[t]he authentic self is not something preexistent, nor is it made ex nihilo. It is crafted as a beautiful work of art is crafted and finds its place in the wider context of society and tradition" (43). Very much in line with Lowney's (2009) claim, this study argues that the "genuine being" or authenticity of the performance is, perhaps ironically, produced through co-construction between poet and audience.

This study investigates how a display of authentic performance is a means to achieve the goal of audience connection and what kinds of strategies help negotiate the identity of the poet as authentic within the context of a performance. This research uses a symbolic interactionist framework and Goffman's (1959) theory of dramaturgy to explore the significant strategies involved in constructing an impression of authentic performance and, in turn, achieving successful audience connection by the slam poet as performer. 


\section{$1.1 \quad$ Significance of Study}

Before discussing this topic further, it is important to contextualize slam poetry in the field of professional communication to understand the significance this research can provide to the larger scene. Professional communicators create products of interaction with their audiences, and this project studies slam poets as professional communicators who do just that - who aim to create a product of interaction with their audience through a variety of elements in their performance. In so doing, they strive to develop acceptable and credible images of themselves. This type of identity work requires ongoing assessments and negotiations of the identities involved in the interaction. Additionally, by analyzing the processes that slam poets employ for achieving a sense of authenticity both on and off the slam stage, we can explore how slam poetry is produced and then, ultimately, consumed and understood. Furthermore, what this research may discover about the construction of authenticity for slam poets, as producers of a message, can likely be applied to how other professional communicators create credibility throughout their own particular processes of message making and production.

\subsection{Objectives of Study}

This exploratory research project has the following objectives: 1) to determine how slam poets make sense of their place and identities in the slam world; 2) to explore how slam poets negotiate their identities with their audience (i.e. the processes of performance preparation); 3) to discover how slam poets create a sense of authenticity through their performance; and 4) to discuss the ways that this micro level analysis of slam poetry can shed light on wider social processes and communication practices across 
other social actors and message makers.

\subsection{Literature Review}

Slam poetry has become a growing cultural art movement that allows its poets, both professional and amateur, a chance to take ownership of their written words and verbally communicate a message (i.e. opinion, thought, emotion, idea) to their audience and wider public. The literature shows several ways that slam poetry has been explored over the years and provides information on slam poetry's history and development. The following section discusses the various elements of slam poetry found in recent literature as well as reviews the concepts of authenticity and identity construction as they relate to the larger scope of performance art.

\subsection{The Slam Scene}

To lay the framework for understanding how slam poetry serves as a unique space for message making, it is important to first briefly address its history and current practice. Slam poetry emerged at a time of critical debate in which poetry was announced to have lost its place in intellectual culture. Somers-Willet (2003) notes that poetry critic Joseph Epstein claimed in his 1988 editorial in Commentary magazine that "however much contemporary poetry may be honored, it is, outside of a very small circle, scarcely read. Contemporary poetry is no longer a part of the regular intellectual diet" (15). Poet-critic Dana Gioia (1992) responded to this claim when he argued that poetry had lost its larger non-academic community because of poets who "abandoned the working-class heterogeneity [...] for the professional homogeneity of academia" (12). Both critics reasoned that if poetry were to be restored, it would be necessary to change the face of 
poetry, attract the general reader, and "seek an audience outside of the academy" (Somers-Willet, 2003:2).

In the midst of these years of poetical debate, Marc Smith, a white, middle-class, ex-construction worker-turned-poet, wanted a new venue for poetry that attracted audiences outside of the academic world and elite circles. In 1986 at a Chicago night lounge, he let the audience judge his on-stage poetry performances and found a format that developed into the basis of the official poetry slam competitions known around North America today (Somers-Willet, 2003).

Slam poets perform their work at poetry slam events, which are staged in locations such as bars, coffeehouses, galleries, universities, and theatres. Five randomly selected audience members serve as official judges for the event while the rest are free to boo, applaud, or make their pleasure or displeasure known to the performer (SomersWillet, 2005). On the national competition level, slam organizations arrange for well known, accomplished, or award winning slam poets to serve as guest judges. On a performance level, Bruce \& Davis (2000) describe slam succinctly and appropriately as "an Olympics of poetry" (121).

Moreover, Low (2006) extends the review of the poetry slam scene by asserting that slam poetry is a 'low tech' genre because it only requires a stage, a performer, and an audience. Within the context of popular culture studies, slam poetry uses traditional forms of entertainment such as competition, language, story telling, and self-expression. However, Low (2006) notes that slam poetry, even in its 'low tech' form of entertainment, cannot help but become "a creation of its technologized context" (100). Through contemporary communication technologies such as online video sharing 
channels, chat rooms, spoken word record labels, and television sitcoms and documentaries that are produced to showcase slam poetry onto the screen, the expansion of the slam audience and other related communities of interest has become inevitable. But whether slam poetry is examined in the offline or online context, Low (2006) proposes that it is essentially a descendant of the oral tradition. Regardless of the fact that a poem performed at a slam event is typically written in advance by the poet, Low (2006) argues that it only truly "comes to life in performance and exists in the communion of poet and audience" (104).

\subsection{The Slam Discourse}

Although sometimes rowdy events, slam poetry competitions have allowed new standards of discourse, shown through writing, tone, subject matter, and performance methods, to emerge. Slam poetry is performed quite commonly as a first-person narrative and many poets transform the stage into a political event, where topics passionate and relevant to their self-identity and their position in society are publicized (Somers-Willet, 2005). Additionally, the slam poetry culture is generally open for anyone to participate in, whether as a performer or a member of the audience. However, because identity and political views are the primary rhetorical frameworks that slam poets employ for their performances, this phenomenon has been widely attractive to and associated with marginalized individuals, particularly women and people of colour (Somers-Willet, 2003). As Low (2006) notes, slam poetry "announces itself as poetry of the margins" (102). It is important, then, to identify how slam poetry forms this culture, and additionally, what the term 'culture' represents to the slam community. 
Through illustrating the many different definitions that have been developed over time, Eagleton (2000) concludes that "the word 'culture' is both too broad and too narrow to be greatly useful," but can be "loosely summarized as the complex of values, customs, beliefs and practices which constitute the way of life of a specific group" $(32,34)$. Eagleton's (2000) claim that ““[c]ulture' at first denoted a thoroughly material process, which was then metaphorically transposed to affairs of the spirit" (1) is particularly significant to the construct of slam poetry. Slam, as it occurs in a very public space, "is a device to politicize the masses on issues they would not readily think about" (Stoval, 2006:70) and to ultimately appeal to the 'affairs of the spirit' to which Eagleton (2000) refers. Therefore, slam poets, as artists and performers, are responsible for communicating their work in a way that will get their slam audience to listen (Stoval, 2006). To do this, they must create a connection that their audience identifies as intimate and authentic. This perception is typically achieved by including confessional moments and emotional appeals in their performances (Somers-Willet, 2009) and must be accomplished without the use of props and only through vehicles of the human body, such as voice, spoken words, and gestures.

As with any public message maker, slam poets perform with the notion that their work will be recognized as a statement in response to a particular subject. Whether their statements are performed in a dramatic, comedic, sensual, personal, or political way, their aim is to create an authentic connection to their audience (Somers-Willet, 2009). To do this, they strategically use language as a way to create common meaning, and although improvisational and freestyle performances exist, "most slam poets write, time, rehearse, and memorize their work before performing it" (Somers-Willet, 2005:51). 
As Cheek (2004) eloquently explains, "[e]ven the language that we take to be the most 'natural,' that is, the spoken word or talk, does not 'have' universal meaning but is assigned particular meanings by both speakers and listeners according to the situation in which language is being used" (1144). Therefore, what is performed on stage may not necessarily have the same effect for its audience if the language spoken - the discourse is presented in a different context or environment or in front of a different group. This notion reinforces the reality that different poetry venues often attract different audience members given their distinct location or culture, making it necessary for poets to acknowledge the possibility of different interests in poetry across different sets of audiences so that the meaning inferred by their words transmits to the audience in a way that creates common understanding of the text presented.

\subsection{Identity and Authenticity in Slam Performance}

The literature asserts that the most successful slam poets are those who connect with their audience on an emotional and impactful level (Somers-Willet, 2005). In the context of this present study, the concept of authenticity construction constitutes a significant element in achieving this emotional and impactful connection as it helps the performer to create a believable and honest identity of themselves to the audience.

Moreover, the cultural politics found in slam poetry are wide-ranging and refer to issues regarding anything from its performance style, to subject matter, to audience perception and involvement, to its discursive influence on public thought. Somers-Willet (2005) notably explains how slams, "[a]s competitions open to and judged by anyone who wishes to participate, $[\ldots]$ open the door not only to the sociopolitical issue of who 
has access to poetry but also to the critical question of what poetry is and how it should be evaluated" (51).

In her examination of the practice of performing identity in slam poetry, SomersWillet (2005) notes that most slam poets use a first-person, narrative approach to their performances, providing instances of confessional moments or emotional appeals within their poems. As many poets use this defining approach, the topic of identity and identity politics has become common on the slam stage. Not only that, but the characteristics of slam poetry compel poets' proclamations of their identities to be quite central to whether they are perceived by the audience as performing a 'successful' poem. Although what is considered 'successful' ranks subjectively and ultimately depends on those judging, Somers-Willet (2005) proposes that certain characteristics of a poetry performance are conducive to a successful representation of a poet's identity to the audience, claiming that "how slam poets perform their identities is just as important as what they say about their identities" (Somers-Willet, 2005:52).

Through her findings, Somers-Willet (2005) discovers that what makes a slam poetry performance 'successful' is some level of authenticity projected by the poet to the audience. She presents Damon's (1998) description of authenticity as something "that effects a 'felt change of consciousness' on the part of the listener" (53), and this 'felt change of consciousness' continuously proves to be a powerful element for creating a connection between poet and audience. Ultimately, Somers-Willet (2005) suggests that slam poets must then convince "audience members of the authenticity of [their] identity" as this element "is a major component of a poet's success in the slam" (53). Her findings indicate that some of the ways slam poets gain legitimacy and authenticity in their 
performances include using rhetorical techniques typically found in hip-hop music, such as repetition, rapping, powerful tone, and descriptive rhyme.

Much of the following literature demonstrates the struggle of finding a concrete, shared perspective on the definition of authenticity in performance, and as Godlovitch suggests, "[a]uthenticity may seem to carry its own warrant for not only does it connote 'accuracy,' it also connotes a quasi-moral 'genuineness'” (in Kemal \& Gaskell, 1999:167). Similarly, Morrow (1978) states, "the word 'authenticity' has acquired a special meaning, a meaning less precise - less rigid, perhaps - than that given in the OED" (245). In this sense, then, it is perhaps useful to explore the dictionary definition of authenticity so as to gain possible insight about its role in spoken word poetry.

For reference, The Oxford English Dictionary (1989) defines authenticity as "being entitled to acceptance $\ldots$ being authoritative or duly authorized $\ldots$ being in accordance with fact ... being what it professes in origin or authorship, as being genuine." With these definitions in mind, it seems that the concept of authenticity cannot be deciphered using just one human sense, such as the eye alone, and so the OED definition is in fact more complex than Morrow (1978) claims it to be. However, exploring the concept of authenticity in the slam poetry performance context can shed light on such noted definitions of being entitled, duly authorized, factual, etc, and given its multimodal characteristics, slam poetry allows a more holistic examination into the interconnectedness of elements found within constructing a sense of authenticity. 
On a general performance level, Jones' (2002) notion connects closely to what many appreciate about the slam phenomenon - that its roots are grounded in the folklore of storytelling, in the oral tradition of performance to form shared meaning:

Performance itself creates a particular authenticity that is rooted in the present, in the experiences here and now that are collaboratively and improvisationally generated. Performance offers a new authenticity, based on body knowledge, on what audiences and performers share together, on what they mutually construct $[\ldots]$ In this exchange, we find an authenticity that is intuitive, body-centered, and richly ambivalent (14).

Similarly to Jones (2002) perspective, Berger \& Del Negro (2002) refer to Bauman's (1989) notion of performance as a "heightened, aesthetic action oriented toward an other" and emphasize performance as "grounded in an underlying awareness that both the self and the other are subjects, that both the self and other have the potential to experience the world and share their experiences with others" (85). This perspective opens the discussion of authenticity as being co-constructed and defined through human interactions. Particularly in spoken word poetry, the performance aspect of the interaction is explicit, proposing a challenge in understanding how authenticity can possibly be achieved in an environment of communication so clearly recognized as rehearsed.

However, as Middleton eloquently explains,

...words arise out of the speaker, whose bodily presence and identity is their warrant, and whose delivery shows what it means to think and say these words and ideas, indeed, shows what it means to live them for at least the moment of their delivery. The presence of a speaker is a reminder that the words are temporarily invoked from an individual with a particular point of view, a particular body, a particular experience and history (in Kemal \& Gaskell, 1999:224).

In this regard, the poet must extend him or herself beyond the mere presentation of poem content and delivery in such a way as to make the audience believe that for a moment in time, he or she is sharing a part of themselves to the other instead of simply performing to a group audience. 
Conversely, Millal discusses the effect of an object, a person, a moment, etc, as being perceived as inauthentic by the other, and proposes that " $[t]$ o characterize something as inauthentic is in one respect or another to mark a failing in that thing; if something is inauthentic, that is, that fact about it provides us with a reason not to value it, or to value it less highly than we might otherwise have done (in Kemal \& Gaskell, 1999:207-208). In the context of slam poetry, understanding what may deem a performance inauthentic may also help affirm the elements and strategies associated with constructing an impression of authenticity as it relates to achieving the goal of audience connection.

\section{$2.4 \quad$ Knowledge Gaps}

The literature reviewed for this paper outlines the historical background and context of the slam poetry phenomenon as well as provides accounts of how authenticity is broadly defined and also specifically acknowledged in performance terms. However, in regard to performance poetry and spoken word, the literature does not directly address or explore the existence of strategic processes involved in developing an impression of authentic performance. This study aims to reaffirm the notion that authenticity is a constructed work of art that emerges through private preparation strategies by the performer, and is subsequently authorized through strategic performance and interaction with the audience. Conducting this research through qualitative measures provides opportunity to delve into the specific instances and experiences of a small group of slam poets in order to better understand the strategies employed in preparation and executed in performance in regards to achieving authenticity and establishing audience connection. 


\subsection{Theoretical Framework}

Drawing on the experiences of local slam poets, this study addresses the processes of achieving an authentic performance and establishing an audience connection within the workings of the poetry slam scene. This research applies Goffman's (1959) theory of dramaturgy to understand the performance and authenticity achievement of slam poets. Goffman's dramaturgy is attributed to a sociological perspective and falls under the scope of the theoretical framework of symbolic interactionism.

Symbolic interactionism is "the study of the ways in which people make sense of their life-situations and the ways in which they go about their activities, in conjunction with others, on a day-to-day basis" (Prus, 1996:10). Coining the term of symbolic interactionism, Blumer (1969) identified three major premises to explain how human experiences and realities are created through a process of interpretation. First, human beings act towards things on the basis of the meanings that they ascribe to those things. Second, the meanings of these things arise from the social interactions that an individual has with others. Third, the individual modifies these meanings through an interpretive process by encountering and dealing with these things (Blumer, 1969).

Symbolic interactionist and ethnographic researcher Prus (1996) explains that the interactionist approach highlights that "human life is community life; that human life is thoroughly intersubjective in its essence" (10), meaning that individuals in any social group define their situations and experiences through "an acknowledgement or sharing of the gestures, symbols, or language of the other" (Prus, 1997:7). It is important to note that these acknowledgements weigh heavily in the understanding of social reality under the 
subsequent theory of dramaturgy, and will be further examined in this paper in the context of poet-audience interaction.

The symbolic interactionist approach also emphasizes that humans make sense of the world through interactions with others and so, require a community context to make sense of their situations. Community context is simply the shared area in which individuals are located, where symbols or languages specific to that community are shared or acknowledged between humans in that setting (Prus, 1997). Essentially, symbolic interactionism states that the self cannot exist without the other, therefore making the study of human interaction integral to understanding how any group of individuals exist in their own life-worlds.

With the understanding of the larger framework of symbolic interactionism in place, the focus can shift into discussing the process of performing identity through Goffman's concept of dramaturgy. Goffman (1959) presents his theory of dramaturgy by using the theatrical stage as a metaphor to describe people as actors who plan and carry out different performances depending on their audience at hand. His approach to explaining human interaction represents the notion that individuals produce and manage their performances in social encounters to make them believable and convincing to their audiences (Burkitt, 1991). While functional theorists view society as an objective reality where individuals are socialized to perform social roles, Goffman believes that behaviour is guided by established norms and roles specific to a social setting and that people adapt to social order as they create and maintain their own social worlds (Goffman, 1959).

Goffman also asserts that individuals use their 'front stage' or 'region' to represent the appropriate or ideal version of the self for a given setting at hand. An 
individual usually has a variety of these front regions that each addresses its own specific audience. A person's 'back stage' or 'region' is a place hidden from his or her audience where, as Goffman (1959) suggests, techniques of impression management are rehearsed.

Impression management is a process by which individuals attempt to control and influence the perceptions others have of them (Turnley \& Bolino, 2001), and Goffman presents impression management in connection with his concepts of front and back regions. Ultimately, this theory suggests that as an individual continually adjusts his or her front based on the presence of a certain audience, the individual simultaneously engages in the back stage process of impression management. In the context of slam poetry, the notions of back and front regions are significant to a poet's groundwork of constructing and managing presentation techniques. Furthermore, it is worthy to consider how establishing an impression of authenticity through a poet's performance is in part achieved through a linking of Goffman's concepts of back and front regions, as they respectively relate to the offstage preparation and onstage performance strategies that operate within the poetry slam scene.

It may be easy to assume that this information implies that presentational behaviour is manipulative and allows for misrepresentation - at least that is how some impression management theorists view this concept (Tseëlon, 1992). However, in Goffman's original work on dramaturgy, this is not what he intends to say about the presentation of self. Instead, his approach focuses on how self-presentation is a process of negotiation, not manipulation, in which people present different definitions of themselves in different contexts in front of different audiences, who then either accept or challenge the individual's presented self (Tseëlon, 1992:116). Goffman (1959) explains this 
negotiation process further by stating that when "an individual projects a definition of the situation and thereby makes an implicit or explicit claim to be a person of a particular kind, he automatically exerts a moral demand upon the others, obliging them to value and treat him in the manner that persons of his kind have a right to expect" (24). This moral command that Goffman (1959) refers to connects to the earlier definitions of authenticity as being entitled to acceptance, being authoritative, and duly authorized, and so his perspective of presentational behaviour as achieved through negotiation processes acquires some level of merit and worthwhile investigation in the context of the poetry slam environment.

Furthermore, Goffman's theory of dramaturgy serves to explain human interaction "in real life" (Baym, 2010); that is, in offline face-to-face settings. The self, to Goffman, is not a fixed entity residing in an individual; but rather, the self is a social process that emerges and develops as an outcome of social interaction (Tseëlon, 1992:115). Therefore, it is through social interaction that we come to define, and redefine, our self-identities. Within these social interactions, individuals interpret each other's language, gestures, and symbols as a way to reflect, constitute, and understand the self and the role it plays in a given environment (Robinson, 2007). This study analyzes such interpretations as they are addressed by interview participants within the slam poetry context as to allow further understanding into how a concept such as authenticity may be strategically crafted and communally constructed in the given moments of their human interaction. 


\subsection{Methodology}

This exploratory research project was conducted through a qualitative method of inquiry. Although descriptions of people's experiences may also be discovered through documents such as autobiographies, diaries, letters, etc, the method for this project relies primarily on observation, participant-observation, and open-ended interviews so that the researcher could "attempt to convey as fully as possible the viewpoints and practices of these people to others" (Prus, 1996:103).

One of the unique benefits of this method of inquiry is that it gives participants the opportunity to describe their emotions and experiences verbally, and as Pennebaker \& Segal (1999) argue, this form of expression may result in reaching conclusions about the meaning, value, or lesson of the experience. Integrating thoughts and feelings into verbal expression makes it much more likely for individuals to understand and summarize their experience, and as the purpose of this study is to discuss the concept of identity and performance of a group of individuals, the qualitative approach was appropriate for both the researcher and participant because it encouraged participants to verbalize their experiences of authenticity.

Qualitative, semi-structured interviews were conducted with six local slam poets. The interviews were audio-recorded with the informed consent of the participants and were approximately one hour in duration. The interviews were conducted individually and featured open-ended questions (Appendix 1) regarding how they write poems, how they perform poems, how they perform their identity, and how they compete. Following transcription of the interviews, the data were coded and analyzed using the grounded theory approach. 
A method of constant comparison (Lincoln \& Guba, 1985) was used to capture commonalties (i.e. recurring themes, words, and phrases) in the experiences of the participants. This method is intended for studies with multiple sources of data and is appropriate for this study because each participant is considered a separate data source.

For further supporting research, an example of a slam poetry performance previously held in Toronto and uploaded on Youtube was analyzed. This performance was retrieved through YouTube.com (nokian70man, 2007) and serves to assist in further analyzing a portion of the insight gained from participant interviews.

Additionally, a field observation of a poetry slam competition held in the Kitchener-Waterloo region was conducted on April 27 $7^{\text {th }}, 2012$ to develop a greater understanding of the overall workings in the live environment. This field observation provided supplementary background information to gain insight into the structure of the competition as well as the various poem content and delivery methods applied by the poets in real time.

\subsection{Sampling Method}

To conduct this study, ethics approval was secured from Ryerson University Research Ethics Board on March 26 $6^{\text {th }}, 2012$. Data gathering consisted of a combination of purposive sampling and snowball sampling. The researcher emailed three different local slam organizations in the Greater Toronto Area and Southwestern Ontario Area and the administrator of each organization sent out a Call for Volunteers via e-mail to their respective network of poets on the researcher's behalf. The email was sent to a total of approximately 60 slam artists and the researcher arranged individual interviews with the first six eligible respondents. The Call for Volunteers email specifically requested 
participation and response from poets who were over the age of 18 and who have competed and participated in slam competitions for at least two years.

\section{$4.2 \quad$ Limitations}

It is important to indicate that the nature of the sample created limitations in the kind of data that could be obtained. This small sample is not sufficient to make any overarching claims regarding the slam poetry culture or to provide exhaustive examples of strategies for constructing authenticity. This data can only account for the experiences of the participants themselves. In addition to the fact that only a small sample was desired because of time constraints, there was also potential for nonresponse bias. Therefore, it was not possible to directly examine whether the poets that responded to the Call for Volunteers e-mail were different in their perspectives from the poets that did not respond, so the findings can still not completely generalize to the larger Toronto and Southwestern Ontario slam poetry population.

\section{$\underline{4.3 \quad \text { Participants }}$}

Three males and three females participated in the research interviews. Experience in performing spoken word poetry ranged from two years to 18 years. Two participants were recruited from a Southwestern Ontario poetry slam organization and four participants were recruited from the Greater Toronto Area poetry slam organizations.

- Participant 1, Male, 30 years old, writing poetry since 12 years old, competing in poetry slam competitions for 5 years

- Participant 2, Female, 22 years old, recent university graduate, competing in poetry slam competitions for 2 years 
- Participant 3, Female, age undisclosed, full-time poet, writing poetry since childhood, competing in poetry slam competitions and performing poetry for 4 years

- Participant 4, Male, 20 years old, current university undergraduate student, competing in poetry slam competitions and performing poetry for 3.5 years

- Participant 5, Male, over 30 years old, performing poetry for 19 years. He founded the first poetry slam organization in Ontario, second in the country to Vancouver, in 1999 in Toronto

- Participant 6, Female, age undisclosed, writing poetry for 6 years, competing in poetry slam competitions and performing poetry for 3 years 


\subsection{Findings and Analysis}

The data compiled from the interview participants offers their understandings about the context of the poetry slam scene, the different purposes for participating in slam poetry, and affords a range of strategies associated with preparing, presenting, and competing in poetry slam competitions. These findings are summarized by (1) context, (2) purpose, and (3) strategy.

\subsection{Context}

Reporting on the general context of the poetry slam scene helps set the framework for exploring the subjective elements of the competition, which are discussed in detail in the two latter categories. The participants provided fairly consistent definitions and understandings of poetry slams and also expressed their views on the rules and judging processes of the competition. The context of the poetry slam scene was divided into the following subcategories: (1) community-centered, (2) emphasis on spoken voice, and (3) competition.

\subsubsection{Community-Centered}

The data shows that there is a strong influence on developing a sense of community in the poetry slam scene. Participant 1 describes the individuals that he has met at poetry slams as "a nurturing group" and "nonjudgmental" with "mutual understanding," who strongly contribute to creating the community focus that allows performers to comfortably "open up and be vulnerable and be strong at the same time." He also mentions Marc Smith, the founder of the slam poetry movement, and explains 
how his poem entitled "Pull the Next One Up" (Appendix 2) embodies the communitycentered approach that the poetry slam scene strives to deliver:

...you wanna be able to uplift the community $\ldots$ the whole poem is just epitomizing the idea that when you get into this, you put your feet in it and you do it - but once you get there, you pull the next one up. So you keep building the community (Participant 1).

Two of the participants, in addition to performing in slam competitions, work as poetry slam organizers. One explains how her team incorporates additional measures to ensure that members feel safe when participating in or attending poetry slams:

... we incorporate trigger warnings; we ask poets to state if their piece is graphic by [raising their hand and giving a "stop" signal]. And for us as organizers, we are trying to take care of our community and care for the people that are coming to our slams. It's not about censoring; it's just about letting people know ahead of time to leave the room or brace themselves for what might come out on stage (Participant 6).

Additionally, four of the six participants mentioned how they have taken their work outside the slam scene and have used the art form as a means of community building in other environments, most notably in schools and for charity organizations.

One participant explains the effect of this experience:

It's a blessing to be able to go to schools and at a young age be able to heal and build community through the arts. That's something that I've always wanted to be a part of. I didn't ever think it'd be through this medium - I always thought it'd be as a teacher, but I guess in a way I am a teacher, just through alternative means (Participant 3).

Undoubtedly, as all six participants addressed, one of the key

characteristics about the poetry slam culture is the opportunity it allows for community building between its members and the inclusive nature it radiates to society. The following two subcategories discuss how this community-centered environment is shaped and maintained. 


\subsubsection{Emphasis on Spoken Voice}

A distinct characteristic of the poetry slam phenomenon is that it is a pure and simple communication channel for producing messages and engaging in meaning-making processes. One participant eloquently explains how significant and important it is to practice her art in an environment with little dependence on the ever-growing technological modes of communication:

It's such a great way to express yourself, and this thought of communication is I think we forget through all our technology - that this is the oldest form. It's movement and sound. To be able to pay homage to that ancient tradition of communication... (Participant 3).

Similarly, another participant explains the significance of poetry slams as

a refreshing and necessary platform for experiencing real time human connection amid society's dependence and daily exposure to cyber-mediated forms of communication:

In this cyber world where we talk to each other everyday on Facebook but see each other once a year, it's an environment where we actually get to speak where we actually get to be in real space in real time with real people having a shared experience. And I think those are all things that are extremely beautiful as they contrast with the society that we live in, which is moving further and further away from human connections. And it goes back to ... being able to have that human experience when we're going way into this tech world [that is] supposed to bring us altogether, but does a good job at keeping us all apart” (Participant 5).

There is also something very intriguing about perfect strangers gathering together to share their often quite personal stories to others in face time. There is no computer screen to hide behind and so the poets, whether professional or amateur, become quite vulnerable to the crowd sitting before them. The emphasis on storytelling through live performance with no use of props ensures that messages are transmitted using only the body and voice, in turn providing focus on the movement and sound of the poet on stage. In this sense, one participant explains that community is developed through the common 
understanding that poetry slams serve as a unique space to "learn about people's lives ... it's not just what you can learn about in a book or in the news. You're hearing voices talk about lives lived and lives that have struggled and lives that have loved" (Participant 2, emphasis added).

\subsubsection{Competition}

An essential element of the poetry slam that sets it apart from all other forms of spoken word and performance poetry is that it is a competition whereby poets' performances are judged by five randomly selected audience members using very minimal criteria. Judges are told that scores can range anywhere from 0 to 10 and are determined by evaluating qualities such as performance, content, and originality - minimal criteria, yes, but complex, as the data will show.

The interview participants provided their understandings about the unique concept of judging spoken word performances and expressed their thoughts on the rather ambiguous judging criteria given to the slam audience, who are most often members of the general public. With the hustle and bustle of the slam scene, one participant boldly asserts:

The thing about slam is that you can never predict it. You could completely win a slam and if you repeated the entire night and just changed the five judges, you could completely lose the slam. So at the end of the day, it's just these five people's opinions (Participant 5).

Although the five judges are ultimately the ones who deliver the scores, they are inevitably influenced by their surroundings and are certainly affected by audience reactions as the night progresses. A few participants stated that during the official announcements, the emcee or host attempts to proactively curtail such influences by acknowledging the importance of consistent judging; however, the 
reminders often work to little avail. One participant explained the inevitable effect of this ever-present influence:

I hate going first; everybody hates it. You know why people hate it? There's something called score creep - the more comfortable the judges get, the more drinks they've had, the more used they get to judging... the scores get higher and higher, and towards the end of the slam everyone's getting $9 \mathrm{~s}$, but in the beginning you see some $7 \mathrm{~s}$ and $8 \mathrm{~s}$ (Participant 1).

Representative of the general response to the discussion, the following excerpt illuminates the conflicting role that judging plays within a culture notably understood to be accepting and supportive to its members:

If I'm bleeding my soul to you, what gives you the right to give me a score? It's like, imagine someone was following your everyday life judging all your relationships. No one has the right to say that a piece of yourself that you chose to share is worth a 7.5. It should be a 10 out of 10 (Participant 4).

Ultimately, however, this participant follows up by asserting, "You do take the risk when you compete - you're well aware that people are going to be judging you, and if you're not up to that challenge, stick to open mic." This view appropriately exemplifies the next theme in the findings, which shows that although the competition is significant to the culture, participants consider it trivial to their underlying reason for performing, as summarized by Participant 3:

...it's all a part of the game ... At the end of the day it's stepping up my game and challenging myself. It's not about the points; I can care less. It's just bettering myself as a performer and a writer, and it's one avenue where I can really craft what I do.

Since the competition, audience involvement, and influences in judging are understood as "all a part of the game," another participant explains the approaches that some slam organizers take to minimize these inconsistencies and influences in judging:

We don't encourage the judges to give high scores and be always positive just because someone has the courage to be on stage, because we also don't want 
poetry on stage that people don't like, and we want people to be honest about it. We've found some good strategies for making that happen. For example, the judges are given a score sheet so they can write down their scores and refer to them throughout the night. We also offer a sacrificial poet $^{1}$ at the beginning and that counters the first score of the night. And with the score sheet, the judges are able to remember the score they gave to that poet and to always judge by that. And on the sheet we have reminders like 'Be Consistent!' (Participant 6).

This excerpt sheds light on how the competitive aspect functions

positively for members instead of producing the typical aggressive nature found in environments of competition. The emphasis on the former characteristics of the slam culture as being community-centered and focused on spoken performance help manage the competitive nature of the art form between poets. Interestingly, in fact, one participant notes how the competition still contributes to supporting the culture's community-centered nature, specifically because of the audience involvement in judging. In this regard, Participant 6 explained that audience members, made up of citizens from the locality, select the poets who represent their city on the national competition level. This responsibility instills a sense of inclusivity and respect towards members and so contributes to the culture's central focus on community building.

\footnotetext{
${ }^{1}$ After the open-mic and just before the competition begins, the host will often bring up a "sacrificial poet" whom the judges score in standard slam fashion in order to practice and calibrate their judging for the actual competition.
} 


\subsection{Purpose}

The poetry slam as a communication medium offers unique experiences to its poets and audience members, as well as meaningful purposes to society at-large. The interview participants showed a purposeful involvement in the slam scene by identifying their underlying goals for performing spoken word and presenting an appreciation of the overall purpose of slam poetry. Additionally, all participants noted a sense of personal worth and benefit through the work they provide to the art form. The different purposes for participating in poetry slams that emerged from the data are divided into (1) personal purpose, (2) social purpose, and (3) real purpose - "real" purpose being understood as the ultimate underlying principle for their work, which is achieved through authentic performance.

\subsubsection{Personal Purpose}

Two distinct personal gains from competing in poetry slams surfaced in the interviews. For the participants, poetry slam competitions not only provide the opportunity to (a) earn cash and win a title, but they also serve as a tool for (b) professional growth and networking.

\subsection{1a Winning}

Interestingly, and perhaps modestly, many of the participants did not care to dwell on the discussion of winning competitions. In their slam career thus far, all the participants have either won a slam competition, placed as a runner-up, or have scored enough tallied points throughout a season to join their local team in competing at the national level. Nonetheless, the general review from the participants is that winning the 
competition, earning a title, and receiving the cash comes secondary in their reasons for performing, although it is "always on your mind" (Participant 4) simply because of the existence and possibility. Still, Participant 2 shares an experience that sheds light on the differing levels of significance that winning the competition has to slam participants:

I recently had a situation on the Internet where this poet was trying to make his way down to the city to slam ... and was asking so many questions about the money ... so I wrote ... "It's not just all about the money; I can't wait to meet you and hear your poems"... [But] I thought, Hmm, well, maybe for some people it is then. [Slam] is a format for people to earn some money, and if writing a poem comes easily to you and you can go and win $\$ 100$, maybe it is about that.

With the above data in mind, it is evident that given the nature of slam as a competition, there is an understandable desire to win on some level as a competing poet; however, Participant 5 notes the issues that arise when poets regard winning as a central motive to their purpose for performing:

...the problem with the slam scene is that many of the younger artists are extremely arrogant, and they feel like: "Well, I'm a slam artist. I've won a few slams, the world revolves around me, everyone knows my name, they cheer for me, I get high scores..." And to me, that person, they haven't transcended into becoming an artist as yet. Because a true artist is more humble and realizes that there are things they have to learn. And the nature of it being a competition means that once you start to win, there's this ego that starts to come from that, that often sets you up to fail because it stands in the way from becoming a true artist and seeing the breadth of what you might be able to create with your art.

This insight suggests that if others perceive a poet as being too concerned with winning the competitions, a sense of inauthentic performance or dishonesty may gradually arise with regards to the poet as performer. This inauthentic performance stems from presenting an egotistical and less humble front region than those considered "true artists," as referred to by Participant 5 above. These perceptions of a poet may not necessarily formulate immediately; however, over time, others may consider that the poet is not performing for a right reason, such as for sharing experiences in an engaging, intimate way with the audience in order 
to build connection and community. In light of Goffman's concept of impression management, these poets might unsuccessfully negotiate their self-presentation, making an implicit claim to their audience that they are performing to win the competition, a feat considered as selfish and dishonest within the slam context. In response, the poet may be subject to a tarnished reputation or, as Participant 5 explained, will likely not be considered a "true artist" in the eyes of others.

\section{$\underline{5.2 .1 \mathrm{~b} \quad \text { Professional Growth/Networking }}$}

Common to the participants' personal purpose for participating in slam competitions is the professional growth and networking opportunities that the art form provides to them, as either professional or aspiring artists. As Participant 4 shares:

It shows me where I rank amongst others, tells me what I need to improve on, what pieces are good in the public eye. I just use it as a facet for improving my work...

Similarly, Participant 1 explains:

I see it as a way to connect with a larger group of people but I also see it as a way to get the most instant and honest feedback of your work. It keeps you sharp; it encourages you to do your best. Sometimes the feedback is brutal and it hurts, but it's honest, and it lets you sharpen your skills.

Additionally, more than half the participants also noted that because

poetry slams are official events, they allow a formal opportunity to network

between artists or with other interested organizations:

... it's to make that connection and to network because every time I step on the stage, it's an opportunity to reach out to people that might not be familiar with my work and then to have opportunities come from that, which is where most of my school bookings have come from 'cause they get a chance to see me ... knowing every time I come to the stage, whether it's slam or open-mic, it's a chance to network (Participant 3). 
On a general note, Participant 5 reflects on the purpose that participating in poetry slams serves for overall personal growth and professional benefit:

I think it really makes you focus on performance, but ... more how it is that you can actually use your voice as an instrument to tell the story that you're trying to tell ... it's a really key thing, being able to take what you've written off of the page and bring it to the stage in a way that could resonate with other people who may or may not have experienced similar things, those that might come from a totally different background or who have a completely different point of reference ... And I think that has been a beautiful challenge for me, just trying to figure out how to take this thing that I have written ... and have somebody else feel this experience.

The "beautiful challenge" that this participant addresses carries over to the

final subcategory, which investigates what constitutes the real personal purpose

for performing, a purpose strong enough to seemingly override the previously

noted dismay felt towards the competitive format of poetry slams. Before arriving

at that finding, however, it is important to discuss the several social purposes

associated with slam poetry.

\subsubsection{Social Purpose}

In the midst of existing in society's constant pool of cultural politics and being inevitably privy to its incessant technological workings, slam participants receive a meaningful and refreshing experience through the slam's unique nature and focus on the oral tradition of communication. Distinctly, these participants believe that the culture of the poetry slam offers a space for (a) social healing and (b) individual human expression. 


\subsection{2a Social Healing}

One participant described the overall social significance of providing a

safe space for individuals to share stories with each other:

The most important thing really ... is a very human element ... I think one of the things that people like about poetry as a form of expression, especially in the slam scene, is that in a society that seems so cold, there's some human elements being brought out - there's compassion, there's empathy, there's telling stories about things that no one's paying attention to, but told in such a way where you don't feel offended by it necessarily, or attacked by it ... and I think the more human the stories are, the more connection people can have and people will make (Participant 5).

At the same time, another participant discussed the individual healing

effect that the slam environment provides to those who attend or participate:

...it gives a space for people to share their voice that is artistic, celebrated in its community building. And the biggest thing ... to me, a poetry slam is successful if at the end of the night, everyone leaves emotionally exhausted. Because they've been pulled all over the map from sadness to joy to hilarity ... just sitting there in an audience, the emotional exercise that you go through in a good poetry slam, I think, is really healthy (Participant 6).

The "emotional exercise" that this participant addresses expresses

Damon's (1998) idea of a 'felt change of consciousness' experienced by audience members when an emotional connection has been made, and which SomersWillett (2005) claims stems from the audience's perception of the poet as displaying an authentic performance of self.

\subsection{2b Individual Human Expression}

Without the use of any props and allowing only voice and body to deliver the performance, slam poets may be perceived as being limited in their forms of expression. Interestingly, however, the structure of the slam competition allows room for innovation and originality during performances. As one participant explained: 
It's art, and art is meant to be accessible ... there's no one form or sound that is better. I've heard people singing their spoken word, and rapping and rhyming and doing crazy limericks ... there's a space for everybody, and why not, we should all have an opportunity to share our voice ... spoken word can be that tool for people to do that. I don't think something like this should be regulated, like $o h$ that kind isn't welcome here, or that thought or that vibe isn't welcome here ... I think everyone's voice regardless of how it's produced or displayed should come to the stage (Participant 3).

Providing a well-rounded perspective of the slam culture from his many years of participation, Participant 5 describes the significance of creating a space that acknowledges and encourages individual expression, and the effect such an environment can have on an individual's sense of empowerment:

Poetry slams are good in that they are often the entry point for a lot of people to find their voice. And I think in a society where fewer and fewer ideas are being freely expressed, it allows people to get up and get three minutes of airtime to share what they think ... A lot of the people in the slam scene start off in the audience and at some point develop the courage to create their own thing and, in so doing, end up finding a voice and finding power in that voice. So, I think it's great in the sense that it affirms people; it affirms their experiences and their stories and it gives people a platform to share and to dialogue.

This cyclical effect of audience member-turned-poet strongly reflects the slam's community-centered approach of "pulling the next one up" and ultimately embodies the slam culture's values of social inclusivity and acceptance.

\subsubsection{Real Purpose}

Apart from the personal purposes of participating in the slam poetry phenomenon and the social purposes accomplished by the slam poetry movement, there lies a poet's underlying goal when performing poetry to a live audience, one that is often constructed and accomplished in their moments of performance. This real purpose embodies the poet's desire to craft a shared experience with the specific live audience at hand. Essentially, this shared experience is achieved through the poet's process of establishing an audience connection. 
Firstly, data findings show that achieving a connection to the audience is often irrespective of, and may not necessarily coincide with, what the judges' scores of the performance may imply. Beyond what the scores convey to the poets, their attempt to create a valuable performance and determine whether they have fulfilled their ultimate purpose of creating a connection in the moment requires (a) knowledge of the live audience at hand and (b) audience responses or acknowledgments during the performance.

\subsection{3a Knowledge of Audience}

All of the participants discussed the importance of knowing the type of audience at hand and provided examples of how audiences differ in their interests of or reactions to poetry. As a seasoned poet and international performer, Participant 5 provides his experience with attending to differing slam audiences:

There's a stereotypical idea of what wins at a slam and I've seen the exact opposite work as well ... it comes down to knowledge of your audience or the room that you're in ... In some places, they want the loud shouting poet and in other places, they just want somebody who is very calm and tells a very beautiful story, and you have to be able to walk into a room and know which one you're in and have enough material that you can pull from to be successful in any kind of environment.

He also acknowledges that most poets who perform in slam competitions are young in their spoken word art and may not always have a large database of poetry to choose from in order to cater to any environment. In this regard, he addresses the challenge that exists when poets perform for only one slam organization or in only the city that they are familiar with:

... a lot of the artists have kinda picked where they will tell their story because that is the audience that they can connect with... and I think you don't really succeed until you figure out how to connect with the other audience that you're running from ... Because if your work doesn't connect with one audience then you have to ask yourself why, what is it about the work that I need to change, 
what is it about the performance, in order to increase the amount of connection that you can make to people (Participant 5).

This insight suggests that poets may quite often take into account the concept of community context, as referred to in the symbolic interactionist approach, when they choose to regularly perform in familiar locations and in front of accustomed audiences. Community context, being the area where symbols or languages specific to that community are shared or acknowledged between humans in that setting (Prus 1997), understandably provides comfort to performers and assuredness that their performance will, on a more secure level, achieve their purpose of audience connection. This notion naturally extends into thinking about the type of strategy work that exists among poets as they come to understand and know their live audience at hand.

\subsection{3b Audience Response and Acknowledgement}

When participants discussed how they realize that a connection is being made with their audience during a performance, they used terms referring to reaction, response, and acknowledgement, such as "outwardly reaction," "being vocal," and "having energy." As Participant 3 shares:

Getting a response from the audience is important, even if it's just a head nod ... I have [a poem] about abuse, and a lot of people are silent out of respect for the nature of the poem but there was still some snapping, a couple grunts here and there from what I was saying ... head nods, just a reaffirmation that I'm there with you ... So, sometimes it's good to have a silent audience, but if it's a highoctane poem and everyone's like cricket cricket cricket, you wonder whether it's getting through to people.

Receiving audience response does not just happen, however. As constantly

expressed in the interviews, there is no one correct formula to performing; however, as

Participant 6 indicates, there is a responsibility on the poets as performers to display 
themselves in a way that invites and encourages a response from the audience during the performance:

It takes everything - writing a good poem on paper, and then performing it in a way that the audience can receive it well. It takes the written words itself, the performance - there's a certain kind of energy that needs to be brought with it, an appropriate energy ... [that] you need to connect with the audience. Confidence from the poet, and conviction behind what they're doing - a certain determination from the poet on stage.

Although this excerpt shows difficulty in pin-pointing exactly what it is needed to "connect," it does reiterate the importance of being invested in the piece and displaying confidence to the audience - two elements in line with the ensuing summary on strategy - which in turn perhaps create response and acknowledgement from the audience as a sign of respect and understanding.

With an understanding of how poets may recognize that a connection has been made to the audience and their "real purpose" fulfilled, the next category focuses on the several strategies that poets employ to thoughtfully construct such audience connection and display an impression of authentic performance to their audience. 


\section{$5.3 \quad$ Strategy}

In order to provide not only an entertaining performance, but also a valuable and meaningful experience for the audience to ultimately achieve audience connection, slam poets employ certain presentation techniques summarized under the following categories: (1) competitive strategies, (2) preparation strategies, (3) performance strategies - and most significant to achieving the "real purpose" - (4) authenticity strategies.

\subsubsection{Competitive Strategies}

Competitive strategies involve the techniques associated with achieving a successful performance in the context of a live competition. As the poetry slam contains a unique feature of live audience judging, it is quite important that poets must not only be mindful of their competitors' performances, but also aware of their audience and the feedback that resonates from the crowd. As each audience is different, continuous strategy work is involved for achieving the goal of making a connection to the specific audience at hand. This sort of strategy work requires a significant level of improvisation on behalf of the poets as their choice of poem and performance technique are often decided only once physically present at the given competition. In this regard, competitive strategies are devised in response to (a) other slam poet competitors, and to (b) the live audience.

\subsection{1a In response to other poets}

Although young in her experiences in poetry slam competitions, Participant 2 acknowledges the competitive existence between poets:

I have heard something about slam culture having a competitive nature, where you have a repertoire of poems and if someone brings out their love poem, you're gonna bring out your love poem and slam it next. So, I have heard of this kind of 
[pause] manipulative process ... but I haven't had that experience yet; my repertoire is not huge.

Shedding light on this comment, all but one participant similarly expressed that they take into account the content of the poetry that is performed by earlier poets at the competition for deciding on their own following poems and presentation technique.

Participant 3 provides an idea of how poets, although prepared with approximately three to five poems for performing, improvise "in the moment" on their choosing of poem in response to the content that others have presented:

I usually go in with three pieces that I practice throughout the day and then also having an extra one or two with me so I come prepared. If someone drops a really heavy piece, I'll try to use something a little more light-hearted to balance it out. 'Cause sometimes it's heavy heavy heavy all night and your heart feels like it's ripping out of your chest like, my goodness! ... So it's to provide that relief as well.

Additionally, Participant 4 addresses techniques on structuring his sequence of

poems in relation to the content already presented by previous competitors in order to excel to the final round:

If everyone's doing sad pieces, I won't do a sad piece. I'll do something to contrast it. And some people say to bring your best poem last, but sometimes there are sets of elimination so what I do is best poem, worst poem, better poem, and hopefully the second poem is good enough to roll me into the third round (Participant 4).

The latter part of this excerpt relates to proactively strategizing for audience judging, and the following subcategory expands on this type of technique.

\section{$\underline{5.3 .1 \mathrm{~b} \quad \text { In response to live audience }}$}

Participant 6 reasserts the suggestion to begin with the strongest poem first, especially when presenting in a different city or with an unknown audience:

In a competition, if no one knows you, you really should start with your strongest pieces first. I was ordering my pieces in a linear narrative with my last one being the strongest and most resonating, but I didn't make it through to perform it - I 
should have started with my strongest to have had a better chance of moving on to the next round.

This suggestion proposes that viewers of a live poetry performance may pay less attention to any logical coordination of the poetry, and so a poet's performances do not have to coincide or relate to one another as a collective to achieve any connection with the audience. Through a symbolic interactionist examination, this insight suggests that the meaning or significance of a poem for the audience arises through a process of interpretation occurring in the instant, whereby the audience generally rates and interprets each performance individually, resulting in leaving room for the poet to negotiate when and how to perform a poem throughout the competition. One negotiation strategy involves being aware of the scores given to previous poetry of the night:

...I try to have three poems ready so if I feel like the room is reacting better to a certain poem, I'll use it. I know this by seeing how they react to other people's poetry. If one person goes up and does a sad poem about someone they knew who died of cancer and they scored really low, another about racism and scores well, social injustice scores well ... sad poem, scores low, then you know don't do a sad poem (Participant 1).

Additionally, poetry slams most often hold an open-mic event directly before the competition begins, allowing members of the audience to sign up and perform an original piece of work. Participant 3 explains how the reactions from open-mic performances are used as another tool for understanding the audience at hand:

Any time you go into a slam ... the audience is always different. So you have to gauge what the audience is feeling and what the vibe is ... Usually after the open-mic, you can have an understanding of how people are reacting. And sometimes, it's really weird but if the audience is invested, there's this collective breath - when something really strikes a cord in people ... and I pay attention and listen to the sounds of slam outside of the poet to really feel the energy that's coming off of the audience.

Evidently, effective competition strategies must take into account the awareness of the audience, as audience members serve as judges and ultimately ascribe the final 
scores to the poet and his or her performance. This discovery helps identify how the categories thus far naturally coalesce and cannot be thoroughly examined without the other, reinforcing the idea that a successful performance, based on display of authenticity to develop audience connection, is co-constructed through the interpretations, perceptions, and interactions found in the poet-audience relationship.

\subsubsection{Preparation Strategies (off-stage)}

Preparation strategies for participating in a poetry slam competition include processes of writing, memorizing, and rehearsing content, delivery, and overall performance. Memorization techniques range from practicing intensely only days before the competition, to recording and replaying the poem on audio, to rehearsing constantly while taking walks, grocery shopping, and every evening before bed. One participant noted his use of a body mirror to rehearse the presentation, "kinda like choreography" (Participant 4), and stated that often, the edits are made not in the content but rather in voice and gestures. Very interestingly, however, was the common response about writing poetry particularly using the slam time-restriction:

Most of the poems, when I'm writing them, I naturally tend to cap them off at three minutes; it just happens. But there are some poems that I write that I will never slam. I never write for slam, I just write and if I think I can slam it, I will (Participant 1).

Additionally, another participant explains:

Since I've been competing in slams, I've been keeping the length to three minutes or less, which has been the biggest challenge - that the poetry is limited by time (Participant 6 ).

In the same regard, Participant 2 provides a thoughtful response to the challenge of being absorbed in writing poetry specifically for the slam scene: 
I would say that is my struggle right now with slam poetry. I'm writing it with a specific event or audience in mind and that's troublesome because [pauses to think], I have all sorts of questions about it still, but maybe that's the way it's supposed to be. Or maybe that's not so freeing and maybe that's not so real, to write a poem thinking of those certain faces and opinions ... And more so lately, I write, and I know who the audience is because I know who comes to our slams in this city. So, that's a great thing because it's very much a community that has blossomed here but, I would also say it's a hindrance...

Moreover, Participant 5 reiterates this struggle as he discusses the limitations that arise when thinking about poetry only in the context of slam competitions:

I've never written a poem for a slam, for a competition. I think ... it's one of the things that keep slam poets in a box in a sense. Because again, you're writing for an event, you're not writing just because there's a story you want to tell ... that's another way that the artists have allowed the slam to define and dictate their art.

\subsubsection{Performance Strategies (on stage)}

Performance strategies are explored in context of the live poetry slam competition and involve techniques of executing both (a) content and (b) delivery of the poem to the slam audience.

\subsection{3a Content}

When asked about the content of their poetry - what it is exactly that they share in their performance - the participants noted that their poems are usually stories about themselves or others they know, and generally encompass all forms of human experience. In essence, the participants strive to produce content that can relate to the audience and ultimately form a connection:

Most of what I write is a very visual story ... a clear narrative ... it's a matter of what words can I use to tell the story so that someone can see what's in my head. I write about everything that humans experience ... stuff around race, racism, identity, immigration, manhood, fatherhood, love; it's all connected and it all comes from that place. I have no poems about anything that has nothing to do with what people go through and experience. All of my poems are about human beings, about our passions, ideas, motivations, disappointments - everything that I write is about the human experience (Participant 5). 
Of course, the creative nature of the art form allows poets to be very vibrant and metaphorical in their storytelling, as Participant 1 exemplifies in his poem summary:

Have you ever heard about the jellyfish that's biologically immortal? There's a jellyfish that, when it reaches full maturation, it can, with intent, take its cells in its body and revert back to the polyp stage and become a baby. And it can do that endlessly, over and over again. But, they're only about $4.5 \mathrm{~mm}$ big and they usually get eaten ... I read about this thing and thought it was amazing, that there's poetry in that ... And see, there is a problem presented in the fact that I talk about how everyone wants to live forever, because nobody wants to die. But if we really did live forever, what would we have? Because what's really beautiful about life is that it ends, there's an ending to it; it's finite. That's an example of the points that I try to drive home in my poems.

Nonetheless, several participants noted that certain content connects better to certain audiences, and so preparing oneself to perform poems of various content during a competition is beneficial for attempting to connect to, and resultantly win over, the audience. As Participant 6 shares:

Because I have only competed in this city, they know me here so I don't worry too much about the content. But if I were to go to other cities, I would strategically choose. With some cities, the scenes respond to super feminist poems, or super political, and that's something to keep in mind if I want to win the slam.

Moreover, a field observation of a poetry slam competition held in KitchenerWaterloo revealed performances regarding the following subject matter: environment, body image, love, consumerism, education, religion, and identity - all of which very much fall in line with the human experience found within individuals' specific lifeworlds.

\subsection{3b Delivery}

All participants were quite frank about declaring the existence of a typical slam style of delivery, a style described as being "the super slammy, throwing-your-hands-upin-the-air, being-super-inspiring-or-really-laying-down-what's-going-wrong-in-the-world 
type. Just in that really serious style, which is ... kinda cliché” (Participant 6). One

participant expands on the discussion and provides specific examples of what can be seen in a "stereotypical" performance:

...stuff that the audience can relate to... pop culture references, you gotta have moments when you're reallyreallyfastanddoingstufflikethis [speeds up pace of speech] and then pausing and gooinnggg like thisssss [slows down pace of speech]. There's a formula to it; it's there ... it's like I'mtalkingreallyfast and I slooooww down cause I'm serrriousss ... and if you throw some f-bombs and a couple of [gestures] and some rhymes in there ... I don't rhyme. I've made it a point not to swear in my poetry. Although I often cuss when I'm talking, I don't like to do it in my poetry - I think it takes away from the message. I don't rhyme phonetically, I don't cuss, I don't have any funny poetry and I don't make pop culture references, so I realized early that I didn't fit the mould ... I did kinda start adjusting myself to the mould at first, and just shocked myself awake you know, you gotta be who you are (Participant 1).

This stereotypical style to slam performance, however, is not the only form of

delivery engaging to the audience. Participant 1 continues and explains how his

connections are often made through his gestures in a performance:

I've gotten a lot of feedback on my hand gestures. I'll have people say stuff like, "It took me there," "I was right there with you man," which I wouldn't get if it was just the content ... The gestures are there to illustrate the moment, what I'm saying. I try to emote the poem through my body. I have a part about a women getting beat by her ex-husband so I go like this [punches fist into palm] and I have a part where I talk about a rising sun and I do this [raises hands], so it's trying to use my hands to illustrate ... I've seen poems without gestures and it depends on the vocal delivery then ... I've seen some where vocal delivery is 10 out of 10 and the hand gesture is just this [chopping movement] over and over again, but it doesn't matter because the voice is so good.

Half of the participants mentioned a renowned spoken word artist from

New York by the name of Jamaal St. John as an example of exceptional delivery.

Jamaal has had a three-time win at the Toronto International Poetry Slam and has

been a four-time finalist at the Nyourican Grand Slam in New York (Nuyorican

Poets Café, 2008). However, two of the three participants mentioned that while

his delivery is engaging and powerful, he often performs his pieces non- 
memorized with a sheet of paper or with his eyes closed for majority of the performance. Nonetheless, they asserted that he is one of the most talented and sincere spoken word artists they have witnessed, adroit at "performing for the ear" through his vocal cadence, annunciation, wordplay, and rhyme choice. An example of one of his performances at the 2005 Toronto International Poetry Slam illustrates his strong delivery against his lack of eye contact or meaningful gestures. $^{2}$ The emphasis that the participants placed on his powerful delivery, while still noting that his gestures are often repetitive or nil, reinforces the strong influence that the spoken voice has on achieving an emotional connection with audience members if projected in an aurally attractive fashion.

Moreover, one participant concludes that "it's about how well you can present it," and remarks that performance delivery is in fact so powerful that it can mask poorly produced content:

You can fake a bad piece with good performance ... no one is going to buy a really good written piece with a bad performance. To be honest, I wouldn't say this is a bad thing either, and this might sound condescending but, people are dumb enough - and I'll throw myself in that group - people are dumb enough to buy what is being presented to them if it's presented well (Participant 4).

This observation unveils an interesting perspective on the concept of impression management and displaying a successful front region on behalf of the poet as performer. Human interaction, as expressed in the Goffmanian approach, represents the idea that individuals produce and manage their performances in social encounters to make them believable and convincing to their audiences. In terms of the slam poet-audience relationship, the poet convinces the audience of

\footnotetext{
${ }^{2}$ View the performance here: nokian70man. (2007). Jamaal st. john 2 [Web]. Retrieved from http://www.youtube.com/watch? $\mathrm{v}=1 \mathrm{aqFL} 5 \mathrm{~m} 4 \mathrm{U} \_\mathrm{Q} \&$ feature=related
} 
their performance of an honest identity by displaying a "good performance," that is, an impression of an authentic front, which can be achieved through delivery techniques such as those claimed by Jamaal St. John.

In the same regard, Participant 5, with his international experience performing spoken word, provides insight into the significance of effective performance techniques in relation to achieving a successful audience connection:

...when I started traveling abroad and doing shows in countries where they didn't speak English, you realize then that it's not even just about the words, but it's about intonation, it's about speed, it's about leveling your voice, when are you loud, when are you soft, and trying to get people to get a sense of what you might be speaking about, even though they can't understand ... a lot of people have said that my voice and my delivery and energy are very therapeutic in a sense and very calming ... you know a lot of people believe that slam is very aggressive and they don't get that from me; it's very warm, very inviting ... I can go somewhere and be in a situation where people don't always understand the words, but don't feel threatened by what I've done on stage...

As the data reveal, content and delivery are obvious elements to a spoken word performance, but are not exhaustive for achieving the real purpose of audience connection. The next final strategy explores elements of performance that assist poets in exhibiting a sense of authenticity to their audience at hand.

\subsection{Authenticity Strategies}

To construct an authentic performance and ultimately accomplish a connection with the audience, poets must exhibit an honest, convincing, and confident persona to their audience, and to do so requires creating an impression of (a) honesty \& personal investment and (b) accurate performance of identity. 


\section{4a Honesty \& personal investment}

All participants declared that displaying a sense of honesty in the performance and being perceived as personally invested in the piece often result in receiving evident support and acceptance from the audience, reflected through high scores and active audience response and engagement. As one participant summarizes:

Sincerity. It's the number one biggest thing. You gotta believe in your poem, then we'll believe your poem ... Sincerity is, it's something you can't explain ... It's the emotional connection that they at least try to make to you. They can have a bad poem but if they tell it from their heart, I'll score it higher than one that has no content... (Participant 4).

When discussing what makes a performance seem dishonest or inauthentic, another participant's response reflects the general notion that the "stereotypical type" of performing in fact seems to be the least convincing:

...the egotistical, I-know-what's-wrong-with-the-world-this-is-what-it-is. The poet kinda places themselves above everybody else and ... says what's wrong with the world and throws out cliché after cliché, things that aren't original and really conceptual - like when they talk about freedom or revolution, I get really skeptical. Give me content rather than buzzwords. That's when the poetry bothers me, when I don't find it new or original in anyway ... My favourite kind of poetry is when it's honest ... when there's storytelling, giving me images that I can move along with in my head (Participant 6).

Here, it seems that the poet successfully expresses an impression of honesty and personal investment when the audience senses that the poet has dedicated effort and thoughtfulness into providing meaningful imagery and specific vocabulary for the audience to interpret and reflect on throughout the performance.

Additionally, to sense that a poet is performing not for the "right reasons," such as those that embody the previous findings of social purpose and real purpose, contributes to the audience's perception of the poet as being inauthentic in his or her performance:

It's just a feeling, a feeling of... it's like a worm in an apple. Like when you taste a bad poem, it's just too fabricated and it doesn't feel real or it feels like the poet is doing it for reasons that maybe have to do with... ego, or satisfying that certain 
way of performing, or with being in the spotlight. Or when it feels like the competition is more important than the poetry (Participant 2).

Furthermore, although storytelling of personal human experience is commonly addressed as appealing to audience connection, it is not the only content that convinces the audience of a sense of personal investment and attachment to the piece from the poet:

I don't think it has to be about people per se; I remember a guy having a great poem about Saskatchewan, but it was real in the sense that you could feel his connection to his words. So it wasn't a monologue, which somebody can write and somebody else could memorize, but you're saying something that has a personal connection to you and people can relate to that personal connection. If someone doesn't feel that you're connected to the words that are coming out of your mouth, then it's hard to make the piece relate to others (Participant 5).

This view suggests that when poets display an impression of a personal investment into their piece, into their words, into their vocal expression, they invite the audience to more fully appreciate the identity presented before them on stage.

To further support this notion, another participant reveals that for a charity event, he performed a poem on a topic that he was not quite knowledgeable and invested in, and admits:

I had to do a lot of research for that poem. And even though it was completed, it wasn't something that I was personally connected with, and like I mentioned before, you can tell when someone isn't really connected to the poem. So even though I performed it I can definitely say it wasn't one of my best pieces (Participant 4).

This excerpt suggests that poets with an honest personal investment in their piece likely devote themselves more meaningfully to the performance and, as a result, present a confident and convincing persona that is reflected in the successful construction of an audience connection. 


\section{4b Identity performance}

Slam audience judges are provided with little to no background information about the poet or poem's content prior to a performance; however, given the nature of the competition, they are required to judge based on how much they enjoyed the poet and his or her piece, while keeping in mind certain criteria. As a result, there is an onus on the performer to manage his or her initial impressions to these individuals, and constructing an authentic persona of the self becomes critical in attempting to build connection to the live audience at hand. Participant 3, who self-proclaims as being gentle, relaxed, and softspoken, provides insight into her set of performances that present her in an opposing light:

It's interesting because I have some pieces that are a little bit gritty, a little raw, and it's a part of me that I don't share on a regular basis. It's more harsh and aggressive ... it's a great outlet to be able to get out those other parts of you that you don't necessarily feel comfortable expressing on a regular basis ... everyone's like "Woah I didn't expect that," and well, it's there. And to deny or ignore it isn't being true to me. So it gives me that opportunity to be loud or outspoken ... but I am very honest with it. 'Cause again, the audience knows you might have a handful of people that have never gone to a slam but they can see through bullsh--, so it's being responsible for what I'm presenting and being authentic on and off stage.

Similar statements about performing identity through a slam performance included that "it can often be a chance to execute a more powerful or loud part of your identity" (Participant 2) and that "it's nice to shock people sometimes [because] it just teaches them not to take things at face value" (Participant 4).

Interestingly, when participants were asked to describe how they self-identify, only one participant acknowledged racial identity. In fact, he was quite honest in discussing how race is a characteristic inevitable to identity impressions and, as a result, is a topic shared frequently in his poetry: 
Identity wise, I just consider myself to be a black male ... everything that I write and create is through that lens of what my experience in life has been ... So I think there's an authenticity that comes from having such a simplistic identity that I work from, because everything that I do, everything that I experience, just comes from: I'm black and I'm male ... if I walk down the street those are the two things that everyone will notice ... None of the other things really come into play at that point, so those are the two main identities that connect to and come through whatever it is that I write and create (Participant 5).

When slam poets write and perform a poem through personal anecdotes, such as racial or gender experiences as expressed by Participant 5, they emphasize the impression that they are revealing a part of themselves and their identity to the audience, which convinces the audience that they are being true to their own character and life-world. In so doing, the audience interprets this impression as an authentic performance and ultimately develops a level of respect and connection to some element of the performance, whether it be the poet, the poet's identity, the content, or the visual or oral delivery. Therefore, the foundation of an authentic performance relies on a convincing display of a poet's identity to the audience at hand, achieved through employing the aforementioned elements and strategies involved in back stage preparation and front stage performance. 


\subsection{Discussion and Future Research}

The focus of this project was to gain a better understanding of how authentic performance is constructed by slam poets as a means to achieve the goal of audience connection. Discovering the kinds of strategies that help the poet achieve audience connection and negotiate their identity as authentic within the context of a performance was also a primary focus of this research. Considering that this study was an exploratory research project, the diversity and small number of participants limited the ability to investigate differences and similarities in the experiences of individuals in other provincial or national regions. Therefore, it is important to note that the findings do not attempt to explain the construct of authentic performance by poets across different locations or from other slam organizations. Rather, the findings are only connected to the experiences shared by the individual participants in the study.

Based on the results, the context of the poetry slam is largely community-centered with an emphasis on the spoken voice for performance. Additionally, the slam scene is unique to the world of poetry performance as it functions through a competition format. The interview participants revealed several of their purposes for engaging in poetry slam competitions. All the participants consider a personal purpose of professional growth and networking as significantly more important than the goal of winning the competition. For the interviewed poets, the social purposes of the slam poetry scene provide feelings of being a part of a special and unique community, one that provides a space for social healing and individual human expression, further embodying the slam culture's values of community and inclusivity. 
The results further revealed a distinguished underlying goal and real purpose for performing: to create audience connection. Although winning the competition is not noted as important for the interview participants, creating a successful audience connection - determined through knowledge of the audience and receiving live audience response and acknowledgement - often results in high scores and, consequently, a closer chance at winning a competition title. Furthermore, influences such as community context (Prus, 1997) and interpretations from the audience in the moment of performance contribute to the necessity of ongoing identity work on behalf of the performer, whereby poets must negotiate when and how to perform a poem throughout the competition in order to most effectively achieve connection. Strategies for creating this audience connection were illuminated in the data under competitive strategies, preparation strategies, presentation strategies, and authenticity strategies.

Preparation and presentation strategies can be explained by Goffman's concepts of front and back regions, where the data suggests that a performance yielding audience connection requires that the poet displays a successful front region, shown to involve displaying an impression of an authentic identity on stage and negotiated and crafted through back region preparation and impression management techniques. Most significant to developing audience connection, then, are the authenticity strategies that emerged in the data. These two distinct strategies allow poets to exhibit an honest, convincing, and confident persona, and involve creating an impression of honest and personal investment in the poetry as well as an accurate performance of identity to the audience. 
In light of these findings, future research may explore how this micro-level analysis of the poetry slam scene and its performers can extend to understanding the workings of individuals in the wider professional communication world. As individual human expression and social healing were pronounced as significant purposes for engaging in slam poetry, it would be interesting to use slam poetry as an approach to pedagogical learning and personal expression in the classroom for youth. As Ellis, Gere \& Lamberton (2003) discover, the language and poetry curriculum focuses on a very narrow range of poetry and writing that is usually written in a form of language uncommon to students' "everyday" language. They refer to Robert Scholes' book The Crafty Reader, where he argues that school curriculum largely takes on a New Criticism literary theory approach in which poetry and language are taught through technical form (ex. learning terminologies and structure) rather than through human experience.

Conversely, the authors detail the experiences of a group of high school students who attended their weeklong summer workshop on slam poetry. The authors note that students engaged in meaningful discussions with each other about the topics they chose to write about and perform and helped one another in making decisions on movement, pitch, tone, and intonation during their performances. Ellis, Gere \& Lamberton (2003) find through their exploration that opportunities to both observe and perform slam poetry in the classroom can be a gateway for students to begin thinking about language and how language unites with voice and gestures to form a cohesive unit that communicates a message.

With the potential benefit of slam poetry in the classroom, it would be interesting to extend the concept into a form of personal and professional training for business 
professionals in the workplace. Mindfulness training is becoming a common strategy that employers use to enhance organizational performance and follower development (Caza, Levy \& Woolley, 2011), suggesting that creating a spiritually and emotionally aware workplace culture with positive and supportive management contributes to lowered stress and higher work ethic and job satisfaction of employees (Khan, 2010; Dane, 2011). Hence, slam poetry could be used as a form of diversity and teamwork training in the workplace, given its success at developing an environment for community-building and social awareness. Moreover, with a growing desire for a presence of authentic leadership in employers and governing organizations (Avolio \& Gardner, 2005; Cooper, Scandura \& Schriesheim, 2005), understanding the elements of successful slam performance and experimenting hands-on with such techniques can extend into a rather holistic form of management training, allowing those in influential positions to practice and engage in authentic leadership development that supports the building of positive environments and socially responsible business practices.

Future research may also examine the ideological workings of the poetry slam through a cultural communications perspective. Commonly found in slam performances, as the data showed, are responses to mainstream ideologies in which political topics, such as gender, race, economy, and environment issues are inevitably addressed. With these political topics appears the discussion of power as well as statements on how it is exercised across social groups. To make such statements, slam poetry involves a specific discourse - authenticity being only one aspect - that allows the poet to successfully elicit an emotional reaction from his or her audience and to also build a voice in response to the topics in question. The power created through this discourse allows slam poets and their 
communities to evaluate and challenge current mainstream ideologies while also creating a safe space to be self-reflexive of their own place in society. As this study explored how poets engage and construct their message production about these issues, an extension to this insight could focus on the kinds of rhetorical power that these messages and the overall slam discourse generate in response to the communications of mainstream ideology. 


\subsection{Conclusion}

One thing is for certain; the insight gained from these participants demonstrates that the perceptions, behaviours, performances, and identities across the poetry slam stage are co-constructed in the moment, as part of an ongoing intersubjective lived experience between poet and audience. Identifiably, this constant co-construction breeds difficulty in explicitly defining how authenticity is created and achieved from poets as performers; however, rather than a discovery of one prescribed formula for achieving authenticity, the data revealed that poets, as producers of a message, engage in a variety of strategic processes that help produce an overall impression of authentic performance to their audience.

This study provided results that reaffirm the notion that authenticity is a constructed work of art that emerges through private preparation strategies on behalf of the performer and is subsequently authorized through community context and strategic onstage performance that is subject to perpetual interpretation by the audience. In all, the performance of slam poetry seems to include a host of forces that work together at a specific moment in time to authenticate the poet's identity, which means that the poetaudience relationship is most definitely a complex and slippery dynamic, but one worthy of exploring for greater understandings of the meaning-making processes found between producers of a message and their audience at hand. 


\section{APPENDIX 1: INTERVIEW SCHEDULE}

1. How long have you been writing poetry?

2. How long have you been performing poetry?

3. How did you first begin competing in poetry slams?

- If only competes: Why do you choose to only compete?

- If competes and also performs in open-mics: Why do you choose to do both?

4. How do you write your poems?

- Do you consult anyone?

- When and how often do you practice?

5. What has your experience been like competing in poetry slams?

6. How do you decide on which poem to perform at a slam competition?

- How do you prepare for your performance?

- Do you write poetry specifically with the intention to competitively perform?

7. What do you think makes a good slam poem and/or slam poet?

8. How do you define your self-identity?

- Do you think your identity is developed or portrayed through your performances? How so?

9. Do you ever think about how your identity is perceived to your audience before, after or during a performance? What comes to mind?

10. What do you want people to get out of your work?

11. Do you perform with a specific goal in mind? What is this goal?

- If it is to win: What do you think are the elements to winning?

12. What does "making a connection to the audience" mean to you? How important is it that your performance makes this connection to the audience?

- Do you think making a successful connection to your audience conveys something about your identity?

- Can you recall a time when you knew that your performance made a connection to your audience? How did you know?

- Can you recall a time when you felt that you did not connect to your audience? How did you know?

13. Have you ever experienced a time when you felt that your audience resisted your identity on stage? How did you handle this moment?

14. In general, what significance do poetry slam competitions have for you? Do you believe there is a place for everyone in the slam poetry world? What makes you believe this?

15. Is there anything about slam poetry that you would like to comment on or add to this interview? 


\section{APPENDIX 2: "PULL THE NEXT ONE UP” BY MARC SMITH}

When you get to the top of the mountain

Pull the next one up.

Then there'll be two of you

Roped together at the waist

Tired and proud, knowing the mountain,

Knowing the human force it took

To bring both of you there.

And when the second one has finished

Taking in the view,

Satisfied by the heat and perspiration under the wool,

Let her pull the next one up;

Man or woman, climber of mountains.

Pull the next hand over

The last jagged rock

To become three.

Two showing what they've already seen.

And one knowing now the well-being with being

Finished with one mountain,

With being able to look out a long way

Toward other mountains.

Feeling a temptation to claim victory

As if mountains were human toys to own.

When you ask how high is this mountain

With a compulsion to know

Where you stand in relationship to other peaks,

Look down to wherefrom you came up

And see the rope that's tied to your waist

Tied to the next man's waist,

Tied to the next woman's waist,

Tied to the first man's waist,

To first woman's waist ... and pull the rope!

Never mind the flags you see flapping on conquered pinnacles.

Don't waste time scratching inscriptions into the monolith.

You are the stone itself.

And each man, each woman up the mountain,

Each breath exhaled at the peak,

Each glad-I-made-it ... here's-my-hand,

Each heartbeat wrapped around the hot skin of the sun-bright sky, Each noise panted or cracked with laughter,

Each embrace, each cloud that holds everyone

in momentary doubt ... 
All these are inscriptions of a human force that can

Conquer conquering hand over hand pulling the rope

Next man up, next woman up.

Sharing a place, sharing a vision.

Room enough for all on all the mountain peaks.

Force enough for all

To hold all the hanging bodies

Dangling in the deep recesses of the mountain's belly

Steady ... until they have the courage ...

Until they know the courage ...

Until they understand

That the only courage there is is

To pull the next man up

Pull the next woman up

Pull the next up

Up

Up. 


\section{REFERENCES}

Alim, H. S. (2011). Global ill-literacies: Hip hop cultures, youth identities, and the politics of literacy. Review of Research in Education, 35(1), 120-146.

Aspling, F. (2011). The private and the public in online presentations of the self: A critical development of Goffman's dramaturgical perspective. Department of Sociology, Master's Thesis: Stockholms Universitet. Retrieved on November 7, 2011 from http://www.essays.se/essay/49934506ef.

“authenticity, $n . "\left(1989,2^{\text {nd }}\right.$ ed). The Oxford English Dictionary Online. Oxford University Press. Retrieved June 20, 2012 from $<$ http://www.oed.com/view/Entry/13325>.

Avolio, B. J., \& Gardner, W. L. (2005). Authentic leadership development: Getting to the root of positive forms of leadership. The Leadership Quarterly, 16(3), 315-338.

Bauman, R. (1989). Performance. In The International Encyclopedia of Performance, ed. Barnouw, E., pp. 262-266. Oxford: Oxford University Press.

Baym, N. (2010) Personal connections in the digital age. Cambridge: Polity Press.

Berger, H. M., \& Del Negro, G. (2002). Bauman's verbal art and the social organization of attention: The role of reflexivity in the aesthetics of performance. Journal of American Folklore, 115(455), 62-91.

Blumer, H. (1986). Symbolic interactionism: perspective and method. University of California Press.

Bruce, H.E. \& Davis, B.D. (2000). Slam: hip-hop meets poetry-a strategy for violence intervention. The English Journal, 89(5, A Curriculum of Peace), 119-127.

Burkitt, I. (1991). The self in everyday communication. Current Sociology, 39(3), 55-82.

Caza, A., Levy, L., \& Woolley, L. (2011). Authentic leadership and follower development: Psychological capital, positive work climate, and gender. Journal of Leadership \& Organizational Studies, 18(4), 438-448.

Cheek, J. (2004). At the margins? Discourse analysis and qualitative research. Qualitative Health Research, 14(8), 1140-1150.

Cooper, C. D., Scandura, T. A., \& Schriesheim, C. A. (2005). Looking forward but learning from our past: Potential challenges to developing authentic leadership theory and authentic leaders. The Leadership Quarterly, 16(3), 475-493. 
Damon, Maria. Was That 'Different,' 'Dissident' or 'Dissonant'? Poetry (n) the Public Spear: Slams, Open Readings, and Dissident Traditions. in Close Listening: Poetry and the Performed Word, ed. Bernstein, C. (1998), 324-342, New York: Oxford.

Dane, E. (2011). Paying attention to mindfulness and its effects on task performance in the workplace. Journal of Management, 37(4), 997-1018.

Eagleton, T. (2000). The idea of culture. EBSCO Publishing: eBook Collection. Retrieved from EBSCOhost: Blackwell Publishing Ltd.

Ellis, L., Gere, A.R., \& Lamberton, L.J. (2003). Out loud: the common language of poetry. The English Journal, 93(1), 44-49.

Gioia, D. (1992). Can poetry matter? In Can Poetry Matter?: Essays on Poetry and American Culture. Saint Paul, MN: Graywolf Press.

Godlovitch, S. Performance authenticity: possible, practical, virtuous, in Performance and Authenticity in the Arts, eds. Salim K. \& Gaskell, I. (1999), pp 154-174, New York: Cambridge.

Goffman, E. (1959). The presentation of self in everyday life. Garden City, N.Y.: Doubleday Anchor Books.

Jones, J.L. (2002). Performance Ethnography: The role of embodiment in cultural authenticity. Theatre Topics, 12(1), pp.1-15.

Khan, S.N. (2010). Impact of authentic leaders on organization performance. International Journal of Business and Management, 5(12), 167-172.

Kemal, S. \& Gaskell, I. (1999). Performance and authenticity in the arts. Cambridge studies in philosophy and the arts. Cambridge University Press.

Lincoln, Y.S. \& Guba, E.G. (1985). Naturalistic inquiry. Beverly Hills, California: Sage Publications.

Low, B. (2006). Poetry on mtv? Slam and the poetics of popular culture. Journal of Curriculum Theorizing, 22(4), 97-112.

Lowney, C. (2009) Authenticitiy and the Reconciliation of Modernity. The Pluralist. 4(1), pp 33-50.

Middleton, P. Poetry's Oral Stage, in Performance and Authenticity in the Arts, eds. Salim K. \& Gaskell, I. (1999), pp 215-250, New York: Cambridge.

Millal, A. Inauthenticity, insincerity, and poetry, in Performance and Authenticity in the 
Arts, eds. Salim K. \& Gaskell, I. (1999), pp 215-250, New York: Cambridge.

Morrow, M. (1978). Musical Performance and Authenticity. Early Music, 6(2), pp. 233-246. Oxford University Press.

nokian70man. (2007, September 5). Jamaal st. john 2 [Video file]. Retrieved from http://www.youtube.com/watch?v=1aqFL5m4U_Q\&feature=related.

Nuyorican Poets Cafe. (2008). Verbs on asphalt - 2008: Jamaal st. john. Retrieved from http://www.verbsonasphalt.com.

O'Connor, E. (2007). The centripetal force of expression: Drawing embodied histories into glassblowling. Qualitative Sociology Review, 3(3), 115-134.

Pennebaker, J.W., \& Segal, J.D. (1999). Forming a story: The health benefits of narrative. Journal of Clinical Psychology, 55, 1243-1254.

Tseëlon, E. (1992). Is the presented self sincere? Goffman, impression management and the postmodern self. Theory, Culture \& Society, 9(2), 115-128.

Turnley, W. H., \& Bolino, M. C. (2001). Achieving desired images while avoiding undesired images: Exploring the role of self-monitoring in impression management. Journal of Applied Psychology, 86(2), 351-360.

Pennebaker, J. W., \& Segal, J. D. (1999). Forming a story: The health benefits of narrative. Journal of Clinical Psychology, 55, 1243-1254.

Prus, R. (1996). Symbolic interaction and ethnographic research: intersubjectivity and the study of human lived experience. State University of New York Press: Albany, New York.

Prus, R. (1997). Subcultural mosaics and intersubjective realities: an ethnographic research agenda for pragmatizing the social sciences. New York: State University of New York Press.

Robinson, L. (2007). The cyberself: The self-ing project goes online, symbolic interaction in the digital age. New Media \& Society, 9(1), 93-110.

Somers-Willet, S.B.A. (2003). Authenticating voices: Performance, black identity, and slam poetry. Faculty of the Graduate School, Doctor of Philosophy Dissertation: University of Texas at Austin. Retrieved on December 1, 2011 from http://repositories.lib.utexas.edu/.

Somers-Willett, S.B.A. (2005). Slam poetry and the cultural politics of performing identity. The Journal of the Midwest Modern Language Association, 38(1, Special Convention Issue: Performance), 51-73. 
Somers-Willett, S.B.A. (2009). The cultural politics of slam poetry: race, identity, and the performance of popular verse in America. The University of Michigan Press.

Stovall, D. (2006). Urban poetics: Poetry, social justice and critical pedagogy in education. The Urban Review, 38(1), 63-80. 